\title{
Effects of sample storage time, temperature and syringe type on blood gas tensions in samples with high oxygen partial pressures
}

\author{
Jeffrey J Pretto, Peter D Rochford
}

\begin{abstract}
Background - Although plastic arterial sampling syringes are now commonly used, the effects of sample storage time and temperature on blood gas tensions are poorly described for samples with a high oxygen partial pressure $\left(\mathrm{PaO}_{2}\right)$ taken with these high density polypropylene syringes.

Methods - Two ml samples of tonometered whole blood $\left(\mathrm{PaO}_{2} 86.7 \mathrm{kPa}\right.$, $\mathrm{PaCO}_{2} 4.27 \mathrm{kPa}$ ) were placed in glass syringes and in three brands of plastic blood gas syringes. The syringes were placed either at room temperature or in iced water and blood gas analysis was performed at baseline and after $5,10,20$, $40,60,90$, and 120 minutes.
\end{abstract}

Results - In the first 10 minutes measured $\mathrm{PaO}_{2}$ in plastic syringes at room temperature fell by an average of $1.21 \mathrm{kPa} / \mathrm{min}$; placing the sample on ice reduced the rate of $\mathrm{PaO}_{2}$ decline to $0.19 \mathrm{kPa} / \mathrm{min}$. The rate of fall of $\mathrm{PaO}_{2}$ in glass at room temperature was $0.49 \mathrm{kPa} / \mathrm{min}$. The changes in $\mathrm{PaCO}_{2}$ were less dramatic and at room temperature averaged increases of $0.47 \mathrm{kPa}$ for plastic syringes and $0.71 \mathrm{kPa}$ for glass syringes over the entire two hour period. These changes in gas tension for plastic syringes would lead to an overestimation of pulmonary shunt measured by the $100 \%$ oxygen technique of $0.6 \%$ for each minute left at room temperature before analysis.

Conclusions - Glass syringes are superior to plastic syringes in preserving samples with a high $\mathrm{PaO}_{2}$, and prompt and adequate cooling of such samples is essential for accurate blood gas analysis.

(Thorax 1994;49:610-612)

There are several theoretical reasons why arterial blood gas tensions may change significantly if there is a time delay between taking the sample and its analysis. As well as the possibility of gases diffusing through the walls of the syringe, the living cells within the sample continue to metabolise oxygen and produce carbon dioxide, thereby reducing the $\mathrm{PaO}_{2}$ and raising the $\mathrm{PaCO}_{2}$. For this reason, arterial blood gas samples are conventionally stored in iced water to slow metabolism and reduce this effect if there is to be any delay before analysis.

When dealing with arterial samples with high oxygen partial pressures (such as with the $100 \%$ oxygen technique for estimating shunt fraction) these effects may be substantially increased. At high arterial $\mathrm{PaO}_{2}$ the pressure gradient across the syringe wall is substantially increased, so the potential error introduced by the diffusion effect is increased. Furthermore, since haemoglobin is fully saturated at these high levels of $\mathrm{PaO}_{2}$, any change in oxygen content has a profound effect on $\mathrm{PaO}_{2}$ because of the relatively low solubility of oxygen in plasma. The effect of cell metabolism on $\mathrm{PaO}_{2}$ is therefore likely to be enhanced, leading to a more profound measurement error than when dealing with the typical "room air" arterial sample.

Earlier studies have documented changes in blood gases in samples stored in glass, ${ }^{1}$ and have compared conventional plastic syringes (usually polypropylene) with glass syringes..$^{2-4}$ More recently, high density polypropylene syringes have been marketed specifically for blood gas analysis. These syringes are claimed to have superior diffusion characteristics over general purpose plastic syringes but published data evaluating them, especially at high levels of $\mathrm{PaO}_{2}$, are scarce. This study was undertaken to document the performance of three types of high density plastic syringes in terms of their ability to preserve blood gas tensions in samples with a high $\mathrm{PaO}_{2}$, and to compare them with glass syringes.

\section{Methods}

Heparinised fresh whole blood (Hb: $15 \cdot 3 \mathrm{~g} / \mathrm{dl}$, WCC: $6.5 \times 10^{9} / 1$, RCC: $\left.5.2 \times 10^{12} / 1\right)$ was exposed to hyperoxic gas $\left(95 \% \mathrm{O}_{2}, 5 \% \mathrm{CO}_{2}\right)$ in a rotating vessel type tonometer (Instrumentation Laboratories model 237 ) at $37^{\circ} \mathrm{C}$ for at least 20 minutes. Samples of $2 \mathrm{ml}$ each were drawn into six glass syringes and six each of three types of plastic blood gas syringes (Marquest "Quik", Terumo "Preza-Pak II" and 
Radiometer "QS90"). Care was taken to flush the syringes several times with the tonometry gas before sampling. Three of each type of syringe were left at room temperature (mean: $22^{\circ} \mathrm{C}$, range: $21-23^{\circ} \mathrm{C}$ ), and the other three of each type were placed in a crushed ice and water slurry. Blood gas analysis (Radiometer ABL500) was performed immediately after withdrawal from the tonometer (baseline) and then at 5, 10, 20,40,60,90, and 120 minutes. Care was taken to eliminate any bubbles from the sample. All samples were periodically agitated during the storage time to ensure adequate mixing. At the completion of all analyses the residual sample volumes were approximately $1 \cdot 0-1 \cdot 2 \mathrm{ml}$.

The measured blood gas tensions were used to calculate pulmonary shunt fraction, ${ }^{5}$ assuming an arterial-mixed venous oxygen content difference of $5 \mathrm{vol} \%$.

\section{Results}

As expected, oxygen partial pressures decreased with time, the changes being lowest for glass and less marked for iced samples. The carbon dioxide tensions tended to rise, but the magnitude of the change was substantially smaller than that of oxygen; again, placing the samples on ice reduced the extent of these changes.

Figures 1 and 2 show the changes in measured carbon dioxide and oxygen tensions from the baseline values over time for the four different syringe types stored at room temperature and in iced water. Each point in the figures is the mean of three measurements. The standard deviations of each group of three measurements averaged $0.08 \mathrm{kPa}(0.6 \mathrm{~mm} \mathrm{Hg})$ for $\mathrm{PaCO}_{2}$ and $2.40 \mathrm{kPa}(18 \mathrm{~mm} \mathrm{Hg})$ for $\mathrm{PaO}_{2}$. The earliest statistically significant change

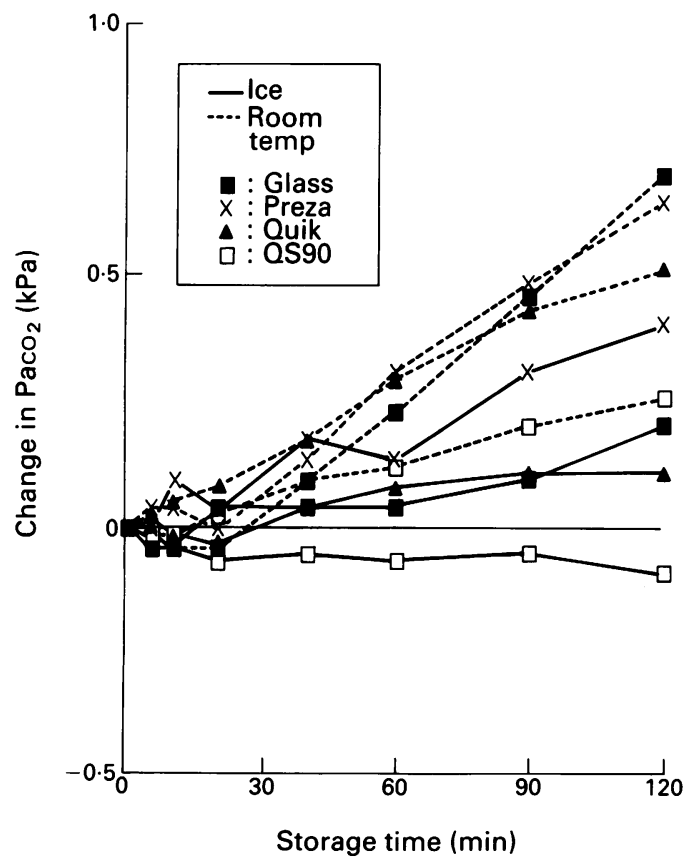

Figure 1 Changes in measured carbon dioxide partial pressures $\left(\mathrm{PaCO}_{2}\right)$ for all syringe types over a two hour storage period. Each point on the graph represents the mean of three measurements. in $\mathrm{PaCO}_{2}$ was not until a storage time of 40 minutes ( $t$ test, $\mathrm{p}<0 \cdot 05$ ). For $\mathrm{PaO}_{2}$ all room temperature samples showed a statistically significant fall at five minutes $(p<0.05)$. Figure 3 shows the effect of these changes with time on the calculated pulmonary shunt for the first $\mathbf{4 0}$ minutes only.

The maximum change in $\mathrm{pH}$ for all syringe types stored on ice was a fall of 0.01 units over the two hour period. All room temperature samples showed a fall of $\mathrm{pH}$ of between 0.04 and 0.05 units over two hours.

\section{Discussion}

This study shows that when samples with a high $\mathrm{PaO}_{2}$ are left at room temperature the oxygen tension falls rapidly in all syringe types tested. In the first 10 minutes the average rate of fall was $1.21 \mathrm{kPa}(9.1 \mathrm{~mm} \mathrm{Hg}) / \mathrm{min}$ in plastic, and $0.49 \mathrm{kPa}(3.7 \mathrm{~mm} \mathrm{Hg}) / \mathrm{min}$ in glass. This contrasts with other published work dealing with samples with a lower $\mathrm{PaO}_{2}$ where no clinically significant changes in $\mathrm{PaO}_{2}$ were observed after 30 minutes at room temperature in plastic. ${ }^{67}$

These changes in $\mathrm{PaO}_{2}$ are of particular importance when estimating shunt by the $100 \%$ oxygen technique. Figure 3 shows how a normal shunt of $1.9 \%$ can be overestimated and fall into the abnormal range $(>5 \%)$ after a delay of as little as five minutes at room temperature in a plastic syringe. On average, for each minute delay between sampling and analysis the shunt value is overestimated by $0.6 \%$ when using plastic syringes.

As expected, the observed changes in $\mathrm{PaO}_{2}$ with time are substantially reduced when the sample is placed in iced water. The average rate of decline in plastic syringes in the first 10 minutes is reduced from $1.21 \mathrm{kPa} / \mathrm{min}$

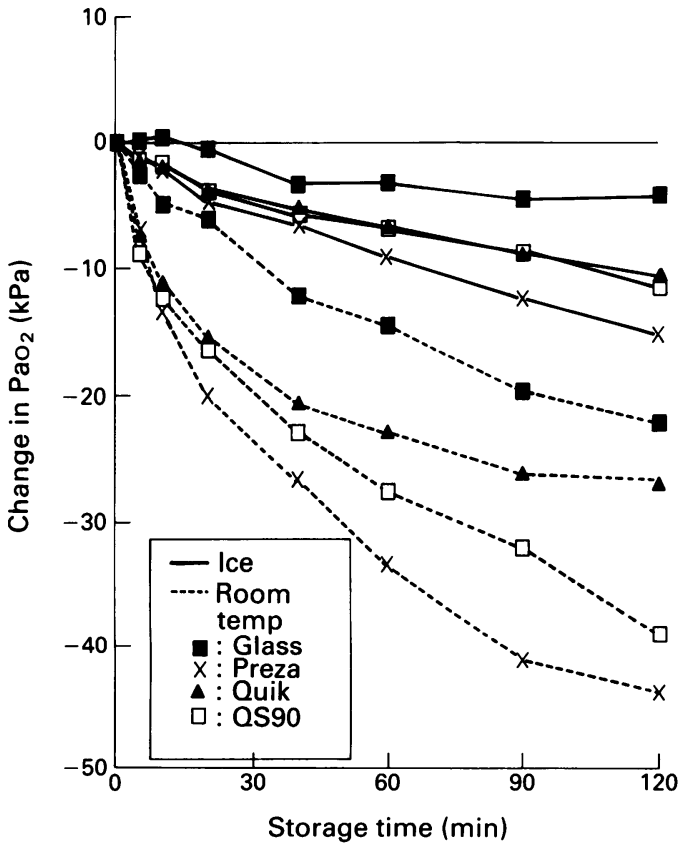

Figure 2 Changes in measured oxygen partial pressures $\left(\mathrm{PaO}_{2}\right)$ for all syringe types over a two hour storage period. Each point on the graph represents the mean of three measurements. 


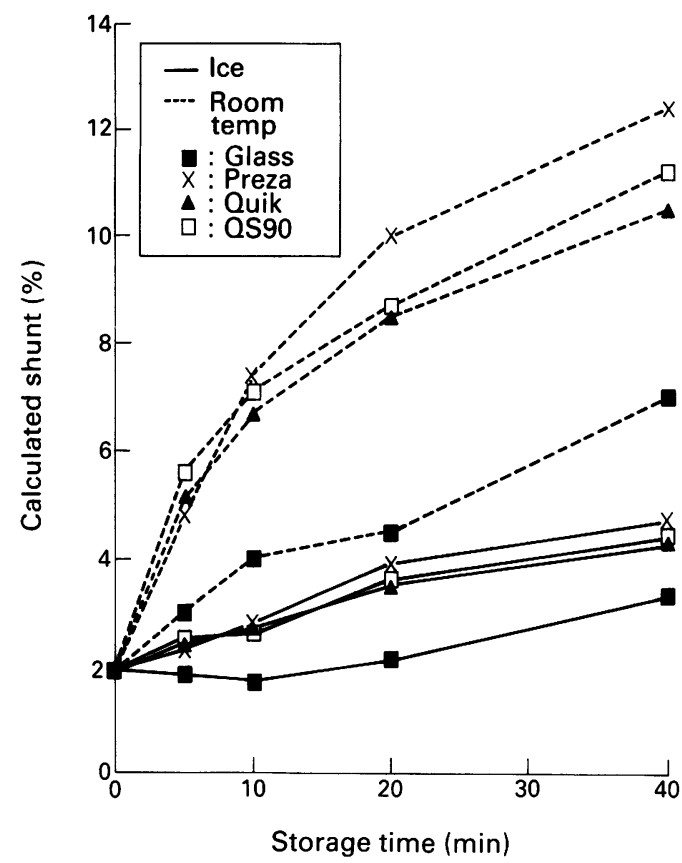

Figure 3 Calculated intrapulmonary shunt for syringe storage times up to 40 minutes. Values for partial pressures shown in figs 1 and 2 were used to calculate shunt and, for clarity, all values were corrected to the same initial shunt value.

$(9 \cdot 1 \mathrm{~mm} \mathrm{Hg} / \mathrm{min})$ at room temperature to $0.19 \mathrm{kPa} / \mathrm{min}(1.4 \mathrm{~mm} \mathrm{Hg} / \mathrm{min})$ on ice. The corresponding effect on calculated shunt is likewise substantially reduced: the delay period required to erroneously interpret a $1.9 \%$ shunt as being abnormal is increased from five minutes to approximately 60 minutes.

Arterial samples for blood gas analysis have traditionally been taken with glass syringes which are impermeable to atmospheric gases. Oxygen and carbon dioxide do not diffuse through the walls of these syringes, so changes with time in tensions of these gases in plasma or water stored in glass syringes are minimal. ${ }^{246}$ Changes in gas tensions observed in whole blood in glass therefore reflect cellular metabolism. Our results for whole blood in glass syringes show that $\mathrm{PaO}_{2}$ declines at an average rate of $0.044 \mathrm{kPa} / \mathrm{min}(0.33 \mathrm{~mm} \mathrm{Hg} /$ $\min$ ) on ice (similar to the value of $0.047 \mathrm{kPa}$ / min reported by Restall et $a l^{4}$ ), and at an average rate of $0.18 \mathrm{kPa} / \mathrm{min}(1.37 \mathrm{~mm} \mathrm{Hg}$ / min) at $22^{\circ} \mathrm{C}$.

The magnitude of the effect of diffusion through the walls of the plastic syringes can be estimated by assuming that the differences observed between plastic and glass result from this diffusion effect only. In the first 10 minutes at room temperature the mean fall in $\mathrm{PaO}_{2}$ observed in plastic was $12.1 \mathrm{kPa}$ (91 $\mathrm{mm} \mathrm{Hg}), 4.9 \mathrm{kPa}(37 \mathrm{~mm} \mathrm{Hg})$ of which was due to metabolism and $7 \cdot 2 \mathrm{kPa}(54 \mathrm{~mm} \mathrm{Hg})$ to diffusion.
Assuming that haemoglobin remains fully saturated and that changes in total oxygen content are therefore due to changes in dissolved oxygen only, the observed changes in $\mathrm{PaO}_{2}$ were used to calculate the oxygen consumption of our blood samples. At $22^{\circ} \mathrm{C}$ the oxygen consumption was $55 \mathrm{ml} / \mathrm{ml}$ blood $/ \mathrm{min}$, and this reduced to $12 \mathrm{ml} / \mathrm{ml} \mathrm{blood} / \mathrm{min}$ when placed in iced water. This is again comparable to Restall's value of $10 \mathrm{ml} / \mathrm{ml}$ blood $/ \mathrm{min}$ on ice. ${ }^{4}$ These figures illustrate that icing the sample does not completely stop metabolism but that it slows it by a factor of four to five.

Although the three types of plastic syringes showed similar changes in the first 10 minutes, there were large differences in the rates of fall in $\mathrm{PaO}_{2}$ subsequently. This is likely to reflect differences in the diffusion characteristics of the syringe walls.

The changes in $\mathrm{PaCO}_{2}$ were far less dramatic than those of $\mathrm{PaO}_{2}$ and averaged a rise of $0.47 \mathrm{kPa}(3.5 \mathrm{~mm} \mathrm{Hg})$ over two hours for plastic syringes left at room temperature. The glass syringes showed the highest average $\mathrm{PaCO}_{2}$ rise $(0.71 \mathrm{kPa}(5.3 \mathrm{~mm} \mathrm{Hg})$ over two hours), probably because, unlike plastic syringes, they do not allow diffusion of carbon dioxide through the syringe walls. The finding that the net change in plastic was an increase in $\mathrm{PaCO}_{2}$ suggests that at these partial pressures the metabolism effect is larger than the diffusion effect.

This study shows that glass syringes are clearly superior to the plastic syringes studied in preserving $\mathrm{PaO}_{2}$ in blood samples with a high $\mathrm{PaO}_{2}$ and should be the syringe of choice when accurate $\mathrm{PaO}_{2}$ measurements are required. Furthermore, $\mathrm{PaO}_{2}$ in such samples showed rapid falls at room temperature for all syringe types including glass. Storage in iced water substantially reduced these errors, suggesting that such samples should always be iced and analysed as soon as possible. Storage of plastic syringes at room temperature for even short periods can result in large errors in calculated shunt fraction.

1 Eldridge F, Fretwell LK. Change in oxygen tension of shed blood at various temperatures. I Appl Physiol 1965;20:790-2.

2 Scott PV, Horton JN, Mapleson WW. Leakage of oxygen from blood and water samples stored in plastic and glass syringes. $B M \mathcal{F} 1971 ; 3: 512-6$.

3 Evers W, Racz GB, Levy AA. A comparative study of plastic (polypropylene) and glass syringes in blood gas analysis. Anaesth Analg 1972;51:92-7.

4 Restall RVF, Miller SE, Hahn CEW, Epstein HG, Foex P. Plastic or glass syringes: a comparison of the changes in oxygen tension when blood or water are stored in iced water. Br $\mathcal{F}$ Anaesth 1975;47:636-7.

5 Cotes JE. Lung function. Assessment and application in medicine. 4th ed. Oxford: Blackwell Scientific Publications, 1979.

6 Mahoney JJ, Harvey JA, Wong RJ, Van Kessel AL. Changes in oxygen measurements when whole blood is stored in iced plastic or glass syringes. Clin Chem 1991;37:1244-8.

7 Liss HP, Payne CP. Stability of blood gases in ice and at room temperature. Chest 1993;103:1120-2. 